\title{
Parâmetros nutricionais e produtivos em bovinos de corte a pasto alimentados com diferentes quantidades de suplemento ${ }^{1}$
}

\author{
Polyana Albino Silva Machado², Sebastião de Campos Valadares Filho ${ }^{3}$, Rilene Ferreira \\ Diniz Valadares ${ }^{4}$, Mário Fonseca Paulino ${ }^{5}$, Douglas dos Santos Pina ${ }^{2}$, Mônica Lopes Paixão ${ }^{2}$ \\ 1 Pesquisa financiada pela FAPEMIG/CNPq \\ 2 Doutor em Zootecnia - UFV. \\ ${ }^{3}$ DZO-UFV. Coordenador do INCT de Ciência Animal. \\ ${ }^{4}$ DVT-UFV. Membro do INCT de Ciência Animal. \\ ${ }^{5}$ DZO-UFV. Membro do INCT de Ciência Animal.
}

RESUMO - Foram conduzidos dois experimentos com o objetivo de avaliar o efeito da quantidade de suplemento sobre o consumo, a digestibilidade, o ganho de peso e a eficiência de síntese microbiana em bovinos de corte. No experimento 1 foram utilizados quatro novilhos Holandês-Zebu, não-castrados, com peso médio de $250 \mathrm{~kg}$, fistulados no esôfago, rúmen e abomaso. O suplemento foi composto por farelo de algodão, grão de milho triturado, mistura mineral e ureia/sulfato de amônio. As dietas foram: controle (sal) e suplementos oferecidos nos níveis de 0,33; 0,66 e 1\% do peso corporal (\%PC). Os consumos máximos de matéria seca (MS), fibra em detergente neutro (FDN) e nutrientes digestíveis totais (NDT) foram estimados em 1,09; 0,73 e 1,20\% do PC. Aumento linear foi observado para os consumos de matéria orgânica (MO), proteína bruta (PB), extrato etéreo (EE) e carboidratos não-fibrosos (CNF). As digestibilidades totais de MS, MO, PB, EE e FDN aumentaram linearmente com o consumo de suplemento, o que não ocorreu com a eficiência microbiana, que não foi influenciada. No experimento 2 foram utilizados 19 animais, zebuínos, não-castrados com idade e pesos médios iniciais de 18 meses e $320 \mathrm{~kg}$. As dietas foram: mantença, controle e ofertas diárias de 1,2 e $3 \mathrm{~kg}$ do suplemento. Aumento linear foi observado para os consumos de MS, MO, PB, EE, FDN e CNF com o aumento das quantidades de suplemento. Consumos máximos de NDT, teor de NDT da dieta e ganho médio diário (GMD) foram estimados quando 2,88; 2,62 e 2,69 kg de suplemento foram ofertados. A quantidade de suplemento teve efeito quadrático sobre a digestibilidade de todos os nutrientes, mas não afetou a eficiência microbiana. A digestão total máxima de FDN é observada para um consumo aproximado de 1,5 kg de suplemento/dia, o que resulta em resposta ótima do ganho médio diário com taxa de ingestão de 400 g de PB.

Palavras-chave: consumo, digestibilidade, eficiência microbiana

\section{Nutritional and productive parameters of beef cattle on pasture fed different amounts of supplement}

\begin{abstract}
Two experiments were conducted aiming to evaluate the effect of amounts of supplement on the intake, digestibility, body weight gain and microbial synthesis efficiency in beef cattle. Four Holstein-Zebu steers fistulated in the esophagus, rumen and abomasum with an average of $250 \mathrm{~kg}$ of body weight were used in experiment 1 . The supplement was made up cottonseed meal, ground corn grain, mineral mixture and urea/ammonium sulfate. The diets were: control (salt) and supplements levels of $0.33,0.66$ and $1.00 \%$ of body weight (BW). Maximum intake of dry matter (DM), neutral detergent fiber (NDF) and total digestible nutrients (TDN) were estimated at 1.09, 0.73 and $1.20 \%$ of BW, respectively. It was observed a linear intake increase to organic matter (OM), crude protein (CP), ether extract (EE) and non-fiber carbohydrates (NFC) intake as supplement offer increased. The total digestibility from DM, OM, CP, EE and NDF increased linearly with the intake of supplement but no affected on microbial efficiency. Nineteen Zebu steers aging 18 months and mean body weight of $320 \mathrm{~kg}$ were used in experiment 2. The diets were: maintenance, control (salt), and the daily supplement offer of $1,2 \mathrm{and} 3 \mathrm{~kg}$. It was observed linear increase in DM, OM, CP, EE, NDF and NFC intake as supplement offer increased. Maximum intake of TDN, diet TDN content and average daily gain (ADG) were estimated to occur as 2.88, 2.62 and $2.69 \mathrm{~kg}$ of supplement offer, respectively. A quadratic effect was observed for total digestibility in all diet components. The microbial efficiency was not influenced by diet supplementation. The neutral detergent fiber digestibility is highest for a intake of approximately $1.5 \mathrm{~kg}$ of the supplement/day, which results in the best response to the ADG obtained with the intake of $400 \mathrm{~g}$ of CP.
\end{abstract}

Key Words: digestibility, intake, microbial efficiency

Recebido em 19/5/2009 e aprovado em 10/6/2010.

Correspondências devem ser enviadas para: polyana.silva@ufv.br 


\section{Introdução}

Os sistemas de produção de carne bovina no Brasil utilizam como substrato básico as pastagens, que constituem 99\% da dieta dos animais (Paulino et al., 2004). Desse modo, a produção de carne a pasto segue a sazonalidade da produção das forrageiras, em que a curva de crescimento dos animais apresenta ganho de peso satisfatório durante a estação chuvosa, e dificuldades em ganhar ou até mesmo manter o peso durante a estação seca do ano.

O período de transição águas-seca marca uma transição extremamente importante no ambiente forrageiro, e neste período pode-se considerar a proteína como limitante no processo produtivo, já que o período marca o início de uma época de escassez das forrageiras, em que os baixos teores desse nutriente na pastagem limitam a atividade dos microrganismos ruminais, afetando a digestibilidade e o consumo de forragem, acarretando baixo desempenho animal.

A estratégia alimentar que há muito tempo vem contribuindo para maior eficiência da produção a pasto é a suplementação de nutrientes. O que se sabe é que a finalidade do incremento da produção através do uso de suplementos é aumentar a eficiência de utilização de forrageiras, sem substituí-las. Dessa forma, atenção especial deve ser dada à quantidade de suplemento oferecido. Em sistemas de pastejo, cabe ao pasto suprir a maior parte dos nutrientes necessários para satisfazer às exigências nutricionais dos animais, não devendo, portanto, o consumo de suplemento substituir o consumo de pasto.

O fornecimento de níveis crescentes de PB via suplementação tem como objetivo encontrar o ponto ótimo de liberação da energia potencial do pasto (Paulino et al., 2008), já que os efeitos da ampliação da disponibilidade de matéria seca potencialmente digestível (MSpd) junto ao sistema de produção são verificados de forma direta através do aumento da disponibilidade dos recursos basais, resultando em decréscimo nos inputs de recursos suplementares ao sistema.

Objetivou-se, então, avaliar o efeito de diferentes quantidades de suplemento para bovinos de corte a pasto sobre os consumos e a digestibilidades totais e parciais dos nutrientes, o ganho médio diário e a eficiência de síntese de proteína microbiana.

\section{Material e Métodos}

Foram conduzidos dois experimentos no Setor de Bovinocultura de Corte da Universidade Federal de Viçosa, durante o período de transição águas-seca, entre os meses de abril e junho de 2005. No experimento 1 foram utilizados quatro novilhos mestiços Holandês $\times$ Zebu, não-castrados, com peso médio de $250 \mathrm{~kg}$, fistulados no esôfago, rúmen e abomaso, distribuídos em um quadrado latino $4 \times 4$, com quatro tratamentos, quatro animais e quatro períodos experimentais, com duração de 14 dias cada. A área experimental utilizada foi constituída de quatro piquetes de 0,40 ha cada um, formados com Brachiaria decumbens Stapf., providos de bebedouro e comedouros individuais.

O suplemento oferecido foi composto por farelo de algodão 38\% PB, grão de milho triturado, mistura mineral 9\% P e ureia/SA - 9:1 (Tabela 1). O objetivo de se variar a composição dos ingredientes no suplemento foi garantir o mesmo consumo de minerais. As quantidades de suplemento fornecidas foram expressas em \% do peso corporal (\% PC) e constituíram as dietas: Controle (apenas sal mineral); 0,33 (0,33\% do PC em suplemento); 0,66 (0,66\% do PC em suplemento) e 1,00 (1\% do PC em suplemento). As quantidades ofertadas de suplemento foram corrigidas a cada período experimental, de acordo com a mudança de peso dos animais, de modo a manter as mesmas proporções.

Para avaliar a composição químico-bromatológica da forragem consumida, foi realizada uma coleta de extrusa.

O fornecimento do indicador aos animais foi realizado entre o $3^{\underline{0}}$ e $12^{\underline{o}}$ dia experimental, na dose de $15 \mathrm{~g}$ de óxido crômico por dia. O indicador foi acondicionado em cartuchos de papel e introduzido diretamente no rúmen dos animais fistulados, diariamente, às $12 \mathrm{~h}$.

Amostras de fezes e de digesta abomasal foram coletadas entre o $8^{0}$ e 13 - dia de cada período experimental, em intervalos de 22 horas. Nas amostras de alimentos, fezes e de conteúdo abomasal foram determinados os teores de MS, MO, nitrogênio total eEE, conforme Silva \& Queiroz (2002). Os teores de FDN foram estimados segundo recomendações de Mertens (2002). A fibra em detergente ácido (FDA) e a lignina em ácido sulfúrico 72\% foram obtidas segundo Van Soest et al. (1991). Os compostos nitrogenados insolúveis em detergente neutro (NIDN) e em detergente ácido (NIDA) foram obtidos segundo Licitra et al. (1996).

Tabela 1 - Composição percentual dos suplementos, com base na matéria natural

\begin{tabular}{|c|c|c|c|c|}
\hline \multirow[t]{2}{*}{ Ingrediente (\%) } & \multirow[t]{2}{*}{$\begin{array}{l}\text { Mistura } \\
\text { mineral }\end{array}$} & \multicolumn{3}{|c|}{$\begin{array}{l}\text { Suplemento } \\
\text { (\%PC) }\end{array}$} \\
\hline & & 0,33 & 0,66 & 1,00 \\
\hline Mistura mineral $9 \% \mathrm{P}$ & 100 & 6,0 & 3,0 & 2,0 \\
\hline Ureia/SA - 9:1 & - & 4,8 & 4,8 & 4,8 \\
\hline Farelo de algodão $38 \% \mathrm{~PB}$ & - & 30,0 & 30,0 & 30 \\
\hline Grão de milho triturado & - & 59,2 & 62,2 & 63,2 \\
\hline
\end{tabular}

Mistura mineral: Fosfato bicálcico, 50\%; cloreto de sódio, 47,8\%; sulfato de zinco, $1,4 \%$; sulfato de cobre, 0,70 ; sulfato de cobalto, $0,05 \%$ e iodato de potássio, $0,05 \%$. 
A quantificação dos CNF foi feita de acordo com a adaptação de Hall (2000), sendo CNF $=100-[(\% \mathrm{~PB}-\% \mathrm{~PB}$ derivada da ureia $+\%$ da ureia) $+\% \mathrm{FDN}+\% \mathrm{EE}+\%$ cinzas $]$.

As análises de cromo nas amostras de fezes foram realizadas de acordo com a técnica descrita por Kimura \& Muller (1967), utilizando-se digestão nitroperclórica e absorção atômica.

A fibra em detergente ácido indigestível (FDAi) foi quantificada nas amostras de alimentos, fezes e sobras por incubação ruminal por 144h. Após a incubação, os sacos contendo a amostra foram lavados em água corrente até a completa retirada dos resíduos ruminais. Empregou-se o sistema ANKOM para as avaliações de FDAi e FDNi nos alimentos, com modificação do saco utilizado $(5,0 \times 5,0 \mathrm{~cm})$, que foi confeccionado com tecido TNT $\left(100 \mathrm{~g} / \mathrm{m}^{2}\right)$.

A excreção fecal foi calculada com base na razão entre a quantidade do indicador fornecido (óxido crômico) e sua concentração nas fezes

O consumo voluntário e os fluxos de MS no abomaso foram estimados empregando-se como indicador interno a fibra em detergente ácido indigestível (FDAi).

As amostras de digesta ruminal, para posterior isolamento de bactérias, foram coletadas no $14^{0}$ dia, quatro horas após o fornecimento do suplemento. As bactérias foram isoladas conforme técnica descrita por Cecava et al. (1990). Para quantificação da síntese ruminal de proteína microbiana utilizaram-se como indicadores as bases purinas, conforme técnica descrita por Ushida et al. (1985), e os derivados urinários de purinas.

Amostras spot de urina $(30 \mathrm{~mL})$ foram coletadas através de massagem na uretra, aproximadamente quatro horas após o fornecimento do suplemento.

$\mathrm{Na}$ amostra de urina foi determinada a concentração de creatinina com o uso de picrato e acidificante (kit comercial Labtest). A excreção diária de creatinina (EC) foi determinada pela equação proposta por Chizzotti et al. (2005). O volume urinário foi estimado pela relação entre a EC e a concentração de creatinina na amostra spot de urina. Ainda na amostra de urina foram realizadas as análises de derivados de purinas (alantoína e ácido úrico). A alantoína foi determinada segundo método colorimétrico, conforme técnica de Fujihara et al. (1987), descrita por Chen \& Gomes (1992). O ácido úrico foi determinado através do kit comercial Labtest, sendo a excreção de derivados de purinas (DP) na urina em 24 h calculada multiplicando-se o volume urinário estimado em $24 \mathrm{~h}$ pela concentração dos DP na amostra spot de urina. A excreção total de derivados de purinas foi calculada pela soma das quantidades de alantoína e ácido úrico (mmol/dia).
Para as análises estatísticas, posteriormente à análise de variância, procedeu-se à decomposição ortogonal da soma de quadrados de tratamentos em efeitos de ordem linear e quadrática.

O coeficiente de determinação $\left(r^{2}\right)$ das equações apresentadas foi calculado como a relação entre a soma de quadrados da regressão e a soma de quadrados de tratamento.

Os métodos para estimar a produção microbiana a partir dos derivados de purinas (DP) na urina e bases purinas (BP) no abomaso, foram comparados com base no ajustamento do modelo de regressão linear simples, sendo as estimativas dos parâmetros da regressão testados pela hipótese de nulidade conjunta: $\mathrm{H}_{0}$ : $\beta_{0}=0$ e $\beta_{1}=1$ e $\mathrm{H}_{\mathrm{a}}$ : não $\mathrm{H}_{0 .}$ Adotou-se $\alpha=0,05$. Caso não ocorra rejeição da hipótese de nulidade, conclui-se pela equivalência dos métodos.

Todos os procedimentos estatísticos foram conduzidos por intermédio do programa SAS (1997), adotando-se 0,10 como nível crítico de probabilidade para o erro tipo 1 .

No segundo experimento foram utilizados 19 animais, predominantemente zebuínos, não castrados, com idade e pesos médios iniciais, respectivamente, de 18 meses e $320 \mathrm{~kg}$.

A área experimental destinada aos animais do desempenho foi constituída de cinco piquetes de 2,0 ha cada, formados com Brachiaria decumbens Stapf., providos de bebedouros e cochos cobertos, com dimensões de $2,00 \times 0,70 \mathrm{~m}$.

O suplemento oferecido teve composição semelhante à daquele descrito anteriormente para os animais fistulados. Os tratamentos foram: controle $=$ sal mineral; mantença $=$ duas horas diárias de pastejo e 22 horas em piquete sem cobertura vegetal; dieta $1=1,0 \mathrm{~kg}$ de suplemento ou $300 \mathrm{~g}$ de proteína bruta (PB); dieta $2=2,0 \mathrm{~kg}$ de suplemento ou $600 \mathrm{~g}$ de PB; e dieta $3=3,0 \mathrm{~kg}$ do suplemento ou $900 \mathrm{~g}$ de PB. Após a pesagem inicial, os animais foram distribuídos de forma aleatória entre os tratamentos, sendo o tratamentomantença composto por três animais e os demais por quatro animais. O experimento teve duração de 84 dias, sendo este iniciado em 5/4/2005 e terminado em 27/6/2005.

O ganho de peso total e o ganho médio diário foram determinados através da pesagem inicial e final. A amostragem do pasto consumido pelos animais em desempenho foi realizada via simulação manual de pastejo, na metade do segundo período experimental dos animais fistulados, período este em que foi feita a estimativa de consumo e digestibilidade, durante oito dias, entre os dias 16 e 23/5/2005, sendo cinco dias de adaptação e três dias para coleta de fezes. 
Após a contenção em tronco, o óxido crômico foi administrado via oral a cada animal em dose única diária de $20 \mathrm{~g}$, acondicionada em cartucho de papel, durante os cinco dias de adaptação e os três dias de coletas de fezes, sempre às $12 \mathrm{~h}$. As coletas de fezes foram realizadas quando os animais estavam contidos no tronco, às 16 h, 12 h e 8 h, por três dias consecutivos.

A análise dos alimentos e fezes, a quantificação dos CNF, a determinação dos indicadores (cromo e FDAi) nas amostras de alimentos e fezes bem como a determinação da excreção fecal e do consumo de matéria seca foram feitas empregando-se os mesmos procedimentos descritos para o experimento 1.

A coleta de amostra spot de urina foi realizada enquanto os animais estavam no tronco, no segundo dia de coleta de fezes. A coleta, o processamento das amostras e as posteriores análises foram realizados seguindo os mesmos procedimentos descritos no experimento 1 . Nos cálculos para determinação da produção de proteína microbiana foi utilizada a relação $\mathrm{N}$-purina: $\mathrm{N}$-total média obtida no experimento 1 .

$\mathrm{O}$ experimento foi analisado segundo delineamento inteiramente casualizado. A comparação entre tratamentos foi realizada por meio de contrastes não-ortogonais. Os contrastes estabelecidos foram: mantença versus controle; controle versus suplementados; e os efeitos de ordem linear e quadrática, para os animais suplementados. Para os procedimentos estatísticos, assim como para o experimento 1 , adotou-se $\alpha=0,10$. Os métodos para estimar a produção microbiana, derivados de purinas (DP) e bases purinas (BP) foram comparados com base no ajustamento do modelo de regressão linear simples, sendo as estimativas dos parâmetros da regressão testados pela hipótese de nulidade conjunta (Mayer et al., 1994): $\mathrm{H}_{0}: \beta_{0}=0$ e $\beta_{1}=1$ e $\mathrm{H}_{\mathrm{a}}$ : não $\mathrm{H}_{0}$.
Adotou-se $\alpha=0,05$. Caso não ocorra rejeição da hipótese de nulidade, conclui-se pela equivalência dos métodos.

\section{Resultados e Discussão}

A composição química da Brachiaria decumbens apresentou valores semelhantes nos diferentes períodos (Tabela 2); porém, para os cálculos de digestibilidade, foram utilizados os valores obtidos em cada período. Adotaram-se para os cálculos de determinação da composição química total dos suplementos, os valores tabelados descritos na Tabela Brasileira de Composição de Alimentos (Valadares Filho et al., 2006).

As quantidades de suplemento tiveram efeito quadrático $(\mathrm{P}<0,10)$ sobre os consumos de MS, FDN e NDT (Tabela 3). O consumo de MS máximo de 6,75 kg/dia foi estimado para o nível de 1,09\% PC em suplemento.

O efeito quadrático observado para o consumo de FDN, em função da quantidade ofertada de suplemento, mostrou que o consumo máximo de FDN de 3,95 kg foi estimado quando o consumo de suplemento foi equivalente a $0,73 \%$ PC. Segundo Mieres (1997), as respostas na relação entre a forragem disponível e a suplementação alimentar podem ser aditivas, substitutivas, aditivas substitutivas, aditivas com estímulo e substitutiva com depressão. Sampaio (2007) também observou efeito quadrático para os consumos de MS e FDN (kg), com o aumento dos níveis de proteína.

O consumo de NDT também apresentou comportamento quadrático com as quantidades de suplemento, da mesma forma que o consumo de MS, sendo que o nível de 1,20\% PC em suplemento proporcionou consumo máximo de NDT estimado de 3,99 kg/dia.

Quando o consumo de MS foi expresso em \%PC, observou-se aumento linear $(\mathrm{P}<0,10)$ de acordo com as

Tabela 2 - Composição química e bromatológica da Brachiaria decumbens nos diferentes períodos e dos suplementos

\begin{tabular}{|c|c|c|c|c|c|c|c|c|c|}
\hline \multirow[t]{2}{*}{ Item } & \multicolumn{4}{|c|}{ Brachiaria decumbens (na extrusa) } & \multirow[t]{2}{*}{ Média } & \multirow[t]{2}{*}{$\mathrm{DP}$} & \multicolumn{3}{|c|}{ Suplemento (\%PC) } \\
\hline & P 1 & P 2 & P 3 & P 4 & & & 0,33 & 0,66 & 1,00 \\
\hline Matéria seca & 24,43 & 26,60 & 24,78 & 27,12 & 25,63 & 1,69 & 89,66 & 89,29 & 89,16 \\
\hline Matéria orgânica (\%MS) & 91,01 & 91,25 & 90,89 & 91,86 & 91,25 & 0,43 & 92,36 & 93,63 & 94,73 \\
\hline Proteína bruta (\%MS) & 8,79 & 8,93 & 8,75 & 8,85 & 8,83 & 0,08 & 31,00 & 31,47 & 31,60 \\
\hline $\mathrm{NIDN} / \mathrm{N}$ & 36,41 & 37,20 & 37,71 & 38,12 & 37,36 & 0,74 & 7,22 & 7,49 & 7,59 \\
\hline NIDA/N & 28,19 & 30,41 & 30,94 & 32,19 & 30,43 & 1,67 & 3,15 & 3,26 & 3,30 \\
\hline Extrato etéreo (\%MS) & 2,42 & 2,36 & 2,46 & 2,32 & 2,39 & 0,06 & 2,92 & 3,05 & 3,09 \\
\hline Fibra em detergente neutro (\%MS) & 74,08 & 74,26 & 73,89 & 74,59 & 74,21 & 0,30 & 17,40 & 19,09 & 19,25 \\
\hline Carboidratos não-fibrosos (\%MS) & 5,72 & 5,70 & 5,79 & 6,10 & 5,83 & 0,18 & 49,88 & 48,86 & 49,63 \\
\hline Fibra em detergente ácido (\%MS) & 42,93 & 42,51 & 41,74 & 43,92 & 42,78 & 0,34 & 7,56 & 7,97 & 9,87 \\
\hline Lignina (\%MS) & 6,48 & 6,57 & 7,09 & 7,22 & 6,84 & 0,37 & 1,52 & 1,56 & 1,57 \\
\hline FDNi (\%MS) & 19,35 & 21,37 & 21,49 & 23,03 & 21,31 & 1,51 & 4,26 & 4,76 & 8,02 \\
\hline FDAi (\%MS) & 12,01 & 12,87 & 13,71 & 14,27 & 13,22 & 0,99 & 3,06 & 3,15 & 5,80 \\
\hline
\end{tabular}

$\mathrm{P}=$ períodos; $\mathrm{DP}$ = desvio-padrão da média; NIDN/N = \% nitrogênio insolúvel em detergente neutro no nitrogênio total; NIDA = \% nitrogênio insolúvel em detergente ácido no nitrogênio total; FDNi = fibra em detergente neutro indigestível; FDAi = fibra em detergente ácido indigestível. 
quantidades de suplemento, mesmo efeito observado para os consumos de MO, PB, EE e CNF (Tabela 3). Esses aumentos ocorreram, possivelmente, devido ao aumento no consumo de suplemento, uma vez que esses nutrientes estão em maior proporção, e também ao possível efeito aditivo da suplementação sobre o consumo de MS de pasto.

$\mathrm{O}$ incremento da quantidade ofertada de suplemento aumentou de forma linear $(\mathrm{P}<0,10)$ as digestibilidades totais de MS, MO, PB, EE e FDN, observando-se comportamento quadrático para a digestibilidade total dos CNF (Tabela 4). O aumento das quantidades de suplemento provavelmente elevou os níveis de proteína no rúmen, o que favoreceu a digestão pelos microrganismos, aumentando a digestibilidade de todos os nutrientes analisados.

A digestibilidade de uma dieta é resultado dos efeitos interativos e associativos de todos os seus nutrientes da dieta e não simplesmente do efeito isolado de determinado constituinte. Mesmo no nível mais alto de oferta de suplemento, a digestibilidade da porção fibrosa da dieta não foi prejudicada (Tabela 4), provavelmente devido à obtenção do balanceamento entre a proteína dietética degradável no rúmen e o teor de energia da dieta, uma vez que essa associação ajuda a manter a digestão da fibra, mesmo em situações em que suplementos ricos em amido são fornecidos aos animais (Bodine et al., 2001).

Tabela 3 - Consumo de nutrientes em bovinos de corte recebendo diferentes quantidades de suplemento e teor de nutrientes digestíveis totais das dietas

\begin{tabular}{|c|c|c|c|c|c|c|c|}
\hline \multirow[t]{2}{*}{ Item } & \multicolumn{4}{|c|}{ Suplemento } & \multirow[t]{2}{*}{ EP } & \multicolumn{2}{|c|}{ Efeito } \\
\hline & 0 & 0,33 & 0,66 & 1,00 & & Linear & Quadrático \\
\hline Matéria seca $(\mathrm{kg} / \mathrm{dia})^{1}$ & 4,38 & 5,30 & 6,62 & 6,65 & 0,10 & 0,01 & 0,08 \\
\hline Matéria seca $(\% \text { PC })^{2}$ & 1,80 & 2,08 & 2,22 & 2,50 & 0,05 & 0,01 & ns \\
\hline Matéria orgânica $(\mathrm{kg} / \mathrm{dia})^{3}$ & 4,00 & 4,84 & 6,08 & 6,15 & 0,09 & 0,01 & ns \\
\hline Proteína bruta $(\mathrm{kg} / \mathrm{dia})^{4}$ & 0,39 & 0,62 & 0,89 & 1,05 & 0,01 & 0,01 & ns \\
\hline Extrato etéreo $(\mathrm{kg} / \mathrm{dia})^{5}$ & 0,10 & 0,13 & 0,17 & 0,17 & 0,01 & 0,01 & ns \\
\hline Fibra em detergente neutro $(\mathrm{kg} / \mathrm{dia})^{6}$ & 3,25 & 3,56 & 4,17 & 3,82 & 0,08 & 0,02 & 0,09 \\
\hline Carboidratos não-fibrosos (kg/dia) ${ }^{7}$ & 0,25 & 0,58 & 0,96 & 1,26 & 0,01 & 0,01 & ns \\
\hline Nutrientes digestíveis totais $(\mathrm{kg} / \mathrm{dia})^{8}$ & 2,38 & 3,15 & 4,30 & 4,41 & 0,08 & 0,01 & 0,09 \\
\hline Nutrientes digestíveis totais $(\%)^{9}$ & 54,55 & 59,14 & 64,71 & 68,43 & 0,60 & 0,01 & ns \\
\hline
\end{tabular}
Significativo $\mathrm{P}<0,10$.

${ }^{1} \hat{Y}=4,2992+4,5019 X-2,0636 X^{2}\left(R^{2}=0,9605\right) \cdot{ }^{2} \hat{Y}=1,8167+0,6737 X\left(R^{2}=0,9861\right) \cdot{ }^{3} \hat{Y}=4,1203+2,3014 X\left(R^{2}=0,9115\right) .{ }^{4} \hat{Y}=0,3987+0,6817 X\left(R^{2}=0,9894\right)$. ${ }^{5} \hat{Y}=0,1077+0,0726 X\left(R^{2}=0,9435\right) .{ }^{6} Y=3,1900+2,1957 X-1,5093 X^{2}\left(R^{2}=0,8268\right) .{ }^{7} \hat{Y}=0,2551+1,0215 X\left(R^{2}=0,9980\right) .{ }^{8} \hat{Y}=2,3108+3,6951 X-1,5274 X^{2}\left(R^{2}=0,9234\right)$. ${ }^{9} \hat{Y}=54,6602+14,1752 X\left(\mathrm{R}^{2}=0,9938\right)$. EP = erro-padrão da média.

Tabela 4 - Digestibilidade dos nutrientes da dieta para bovinos recebendo diferentes quantidades de suplemento

\begin{tabular}{|c|c|c|c|c|c|c|c|}
\hline \multirow[t]{2}{*}{ Item } & \multicolumn{4}{|c|}{ Nível de suplemento } & \multirow[t]{2}{*}{ EP } & \multicolumn{2}{|c|}{ Efeito } \\
\hline & 0 & 0,33 & 0,66 & 1,00 & & Linear & Quadrático \\
\hline \multicolumn{8}{|c|}{ Total } \\
\hline Matéria seca ${ }^{1}$ & 53,42 & 57,45 & 60,96 & 63,14 & 0,75 & 0,01 & ns \\
\hline Matéria orgânica² & 56,73 & 61,68 & 62,54 & 64,11 & 0,93 & 0,03 & ns \\
\hline Proteína bruta ${ }^{3}$ & 42,76 & 58,46 & 66,74 & 76,14 & 1,37 & 0,01 & ns \\
\hline Extrato etéreo ${ }^{4}$ & 65,78 & 67,46 & 73,96 & 74,56 & 0,80 & 0,01 & ns \\
\hline Fibra em detergente neutro ${ }^{5}$ & 58,46 & 58,88 & 62,17 & 63,18 & 0,86 & 0,06 & ns \\
\hline Carboidratos não-fibrosos ${ }^{6}$ & 66,04 & 82,05 & 84,06 & 86,15 & 0,90 & 0,01 & 0,01 \\
\hline \multicolumn{8}{|c|}{ Ruminal } \\
\hline Matéria seca ${ }^{7}$ & 50,45 & 55,98 & 63,12 & 64,93 & 1,22 & 0,01 & ns \\
\hline Matéria organica ${ }^{8}$ & 56,92 & 61,25 & 63,00 & 64,98 & 1,36 & 0,07 & ns \\
\hline Proteína bruta ${ }^{9,15}$ & $-24,34$ & 13,21 & 22,38 & 31,19 & 2,55 & 0,01 & ns \\
\hline Extrato etéreo ${ }^{10,15}$ & $-11,62$ & $-8,51$ & $-2,21$ & 0,94 & 1,30 & 0,01 & ns \\
\hline Fibra em detergente neutro & 93,95 & 90,26 & 91,88 & 89,64 & 1,42 & ns & ns \\
\hline \multicolumn{8}{|c|}{ Intestinal } \\
\hline Matéria seca ${ }^{11}$ & 49,55 & 44,02 & 36,88 & 35,07 & 1,22 & 0,01 & ns \\
\hline Matéria orgânica ${ }^{12}$ & 43,08 & 38,75 & 36,99 & 35,01 & 1,36 & 0,07 & ns \\
\hline Proteína bruta ${ }^{13,15}$ & 53,39 & 53,10 & 57,10 & 65,19 & 1,38 & 0,02 & ns \\
\hline Extrato etéreo ${ }^{14,15}$ & 69,44 & 69,86 & 74,31 & 74,27 & 0,88 & 0,05 & ns \\
\hline Fibra em detergente neutro & 6,55 & 9,74 & 8,12 & 10,35 & 1,12 & ns & ns \\
\hline
\end{tabular}

Nível de significância $(\mathrm{P}<0,10)$.

${ }^{1} \hat{Y}=53,8667+9,7990 X\left(R^{2}=0,9818\right) \cdot{ }^{2} \hat{Y}=57,8394+6,8881 X\left(R^{2}=0,8653\right) \cdot{ }^{3} \hat{Y}=44,8427+32,5308 X\left(R^{2}=0,9761\right) .{ }^{4} \hat{Y}=65,5444+9,8415 X\left(R^{2}=0,8966\right)$.

${ }^{5} \hat{Y}=58,0721+5,2357 X\left(R^{2}=0,9142\right) \cdot{ }^{6} \hat{Y}=66,7634+50,2181 X-31,5183 X^{2}\left(R^{2}=0,9602\right) .{ }^{7} \hat{Y}=51,0762+15,1646 X\left(R^{2}=0,9532\right) .{ }^{8} \hat{Y}=57,6690+7,7820 X\left(R^{2}=0,9501\right)$

${ }^{9} \hat{Y}=-22,9145+118,1506 X-65,4091 X^{2}\left(R^{2}=0,8593\right) .{ }^{10} \hat{Y}=-11,9202+13,2002 X\left(R^{2}=0,9788\right) .{ }^{11} \hat{Y}=48,9237-15,1646 X\left(R^{2}=0,9531\right)$.

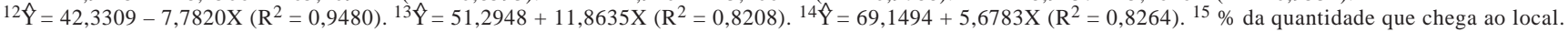


A digestibilidade dos carboidratos não-fibrosos apresentou comportamento quadrático com as quantidades de suplemento e o nível de $0,79 \%$ PC em suplemento proporcionou valor máximo estimado de digestibilidade de $86,76 \%$.

$\mathrm{O}$ aumento da oferta de suplemento proporcionou para os níveis de 0; 0,33; 0,66; e 1,00\% do PC em concentrado, uma dieta consumida com teores de 8,83 ; 11,75; 13,63; e 15,85\% de PB e relação volumoso:concentrado de 100:0; 83:17; 73:27; e 60:40, respectivamente. Os maiores valores de digestibilidade da PB para as maiores quantidades de suplemento (Tabela 4) se justificam pela maior concentração de compostos nitrogenados e por uma possível diminuição de nitrogênio endógeno nos compostos nitrogenados fecais, comportamento semelhante foi observado por Detmann et al. (2005). A oferta de suplemento, no entanto, não alterou $(\mathrm{P}>0,10)$ as digestibilidades ruminais $\mathrm{e}$ intestinais da FDN (Tabela 4) e isso comprova que, mesmo em maior nível de suplemento, não ocorreu alteração significativa do $\mathrm{pH}$, a ponto de reduzir a digestão da fibra. Para a digestibilidade ruminal da FDN (Tabela 4), todos os valores encontrados foram superiores a $90 \%$, comprovando que o rúmen é o local preferencial de digestão da fibra.

Aumentos lineares $(\mathrm{P}<0,10)$ foram verificados para as digestibilidades ruminais da MS, MO e EE com o aumento da quantidade de suplemento. Contudo, as digestibilidades intestinais da MS e da MO diminuíram linearmente $(\mathrm{P}<0,10)$ com o aumento da oferta de suplemento (Tabela 4).

Observou-se comportamento quadrático $(\mathrm{P}<0,10)$ para a digestibilidade ruminal da PB, com valor máximo de 30,44\% para o nível de oferta de suplemento de $0,90 \%$ do PC. O valor negativo observado para o tratamento-controle (Tabela 4) indica que não houve perda líquida de nitrogênio na forma de amônia, o que, segundo Ladeira et al. (1999), pode ser indicativo de deficiência dietética de proteína.
Nos demais tratamentos, observaram-se coeficientes positivos, o que indica possível perda de nitrogênio com o aumento dos teores de PB nas dietas. A digestibilidade aparente da $\mathrm{PB}$ no intestino cresceu linearmente $(\mathrm{P}<0,10)$ com o aumento do nível de suplemento (Tabela 4), comportamento similar ao observado por Dias et al. (2000). O valor obtido para o nível de concentrado equivalente a $1 \%$ do PC foi de $65,19 \%$ (Tabela 4), próximo ao encontrado por Dias et al. (2000) com o nível de 37,5\% de concentrado na dieta.

Valores negativos para os coeficientes de digestibilidade aparente do EE no rúmen foram observados para todos os tratamentos, com exceção do nível de $1 \%$ do peso corporal, indicando síntese de lipídeos microbianos, conforme considerações de Carvalho et al. (1997).

Comportamento quadrático $(\mathrm{P}<0,10)$ foi observado para os valores de alantoína, PBmicBP e MSmic (Tabela 5), com valores máximos de 161,29; 610,54; e 1.214,98 para consumos de 1,$14 ; 1,09$ e $0,92 \%$ do peso corporal em suplemento, respectivamente.

Ladeira et al. (1999) também observaram efeito quadrático para a produção de MSmic quando avaliaram níveis de concentrado na dieta, estimando produção máxima de 848,28 g/dia para o nível de 39,38\% de concentrado. O valor encontrado neste experimento (1.214,98 g/dia) no nível de $40 \%$ de concentrado na dieta foi superior ao obtido por esses autores, possivelmente devido ao maior nível de carboidratos não-fibrosos ingerido pelos animais.

Houve aumento linear $(\mathrm{P}<0,10)$ para as purinas totais $\mathrm{e}$ PBmicDP com a elevação dos níveis de suplemento nas dietas (Tabela 5).

A eficiência microbiana, expressa em g PBmic/100 g NDT, não foi influenciada $(\mathrm{P}>0,10)$ pelos níveis de suplemento, tanto quando foi estimada pelos derivados de purinas quanto determinada pelas bases purinas (Tabela 5),

Tabela 5 - Derivados urinários de purinas, eficiência microbiana, proteína bruta e matéria seca microbianas, obtidos em função do consumo de suplemento

\begin{tabular}{|c|c|c|c|c|c|c|c|}
\hline \multirow[t]{2}{*}{ Item } & \multicolumn{4}{|c|}{ Tratamentos } & \multirow[t]{2}{*}{ EP } & \multicolumn{2}{|c|}{ Efeito } \\
\hline & 0 & 0,33 & 0,66 & 1,00 & & Linear & Quadrático \\
\hline Alantoína (mmol/dia $)^{1}$ & 83,03 & 117,58 & 150,79 & 158,95 & 2,87 & 0,01 & 0,06 \\
\hline Ácido úrico (mmol/dia) & 17,09 & 16,14 & 16,98 & 17,29 & 0.63 & ns & ns \\
\hline Purinas totais $(\mathrm{mmol} / \mathrm{dia})^{2}$ & 100,13 & 133,72 & 167,77 & 176,24 & 3,24 & 0,01 & ns \\
\hline Eficiência microbiana (gNmic/100 gNDT) DP & 12,75 & 14,16 & 13,78 & 14,03 & 0,46 & ns & ns \\
\hline Proteína bruta microbiana (g/dia) ${ }^{3}$ DP & 302,89 & 443,44 & 858,89 & 621,32 & 13,51 & 0,01 & ns \\
\hline Eficiência microbiana (gNmic/100 gNDT) BP & 12,20 & 13,28 & 14,01 & 13,33 & 0,38 & ns & ns \\
\hline Proteína bruta microbiana (g/dia) ${ }^{4}$ BP & 285,68 & 407,28 & 595,30 & 595,71 & 13,87 & 0,01 & 0,07 \\
\hline Matéria seca microbiana $(\mathrm{g} / \mathrm{dia})^{5}$ & 588,02 & 853,79 & 1247,76 & 1182,6 & 39,46 & 0,01 & 0,08 \\
\hline Nitrogênio bacteriano & 7,88 & 7,63 & 7,69 & 8,02 & 0,19 & ns & ns \\
\hline Npurina:Ntotal & 0,1205 & 0,1364 & 0,1229 & 0,1259 & 0,01 & ns & ns \\
\hline
\end{tabular}

${ }^{1} \hat{Y}=81,8212+139,5253 X-61,2384 X^{2}\left(R^{2}=0,9404\right) .{ }^{2} \hat{Y}=105,3350+78,6570 X\left(R^{2}=0,9439\right) .{ }^{3} \hat{Y}=324,6778+329,0571 X\left(R^{2}=0,9339\right)$

${ }^{4} \hat{Y}=272,7747+617,4023 X-282,1331 X^{2}\left(R^{2}=0,8963\right) .{ }^{5} \hat{Y}=558,3151+1416,0792 X-763,4286 X^{2}\left(R^{2}=0,8363\right)$

$\mathrm{DP}=$ derivados de purina; $\mathrm{BP}=$ bases purinas; $\mathrm{N}=$ nitrogênio. 
sendo os valores médios de 13,68 e 13,20 g PB/100 g NDT, respectivamente, que estão de acordo com o proposto pelo NRC (1996) de 13 g PBmic/100 g NDT.

Os valores estimados pelos derivados de purinas (DP) e obtidos pelo método das bases (BP) purinas foram praticamente os mesmos para proteína microbiana (Figura 1 ). A observação do valor $(\mathrm{P}>0,05)$ mostra a equivalência entre os dois métodos de determinação (Tabela 6).

Puchala \& Kulasec (1992) e Perez et al. (1996), comparando os métodos das bases purinas no abomaso e da excreção de derivados de purinas na urina de ovinos, obtiveram alta correlação entre os dois métodos. MartínOrúe et al. (2000), em trabalho com novilhas, relataram que o fluxo de compostos nitrogenados microbianos determinado

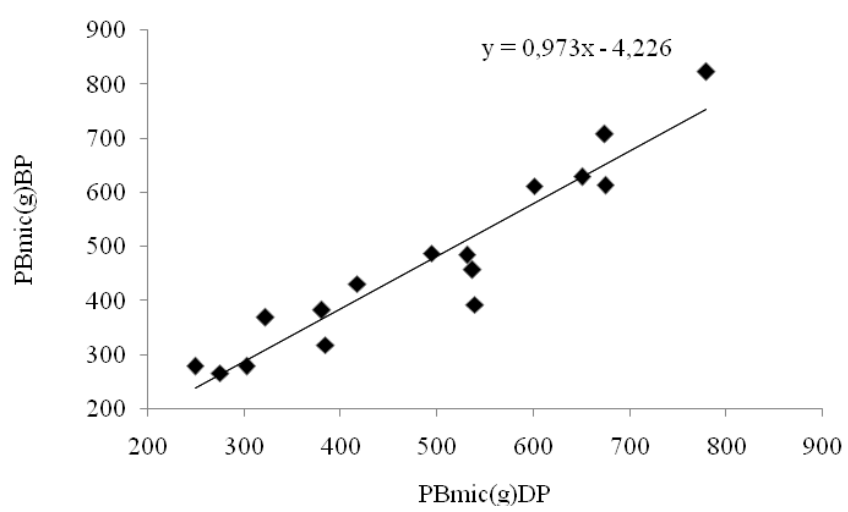

Figura 1 - Relação entre os valores de proteína bruta microbiana obtidos pelas bases purinas no abomaso e pelos derivados de purinas na urina em bovinos em pastejo.

Tabela 6 - Estimativa dos parâmetros da regressão linear para comparação entre os valores estimados de síntese de PBmic obtidas por dois métodos (derivados de purina e bases purinas)

\begin{tabular}{lcccc}
\hline Item & Intercepto & Inclinação & $\mathrm{r}^{2}$ & $\mathrm{P}\left(\mathrm{H}_{0}: \mathrm{a}=0\right.$ e b $\left.=1\right)$ \\
\hline PBmicBP/ & $-4,2212$ & 0,9730 & 0,9011 & 0,4400 \\
PBmicDP & & & & \\
\hline
\end{tabular}

a partir das bases purinas no duodeno e da excreção dos derivados de purinas na urina não diferiu.

Rennó et al. (2000), em estudo com novilhos mestiços e zebuínos, comparando o método das bases purinas no abomaso com o dos derivados de purinas na urina, também verificaram que em ambos os grupos genéticos a produção microbiana pode ser mensurada pela excreção dos derivados de purinas na urina.

$\mathrm{Na}$ análise da composição química do pasto do experimento 2, a qualidade do pasto foi semelhante à do piquete dos animais do experimento 1 (Tabela 7).

No primeiro contraste testado (controle $v$ s mantença), observou-se diferença $(\mathrm{P}<0,10)$ para todas as variáveis analisadas de consumo, desempenho e digestibilidade, exceto para a digestibilidade do EE, evidenciando a relação inversa entre consumo e digestibilidade (Tabela 8).

Os animais do tratamento controle apresentaram maiores $(\mathrm{P}<0,10)$ consumos de todos os nutrientes, enquanto as digestibilidades mostraram-se inferiores $(\mathrm{P}<0,10)$ às obtidas nos animais da mantença, exceto para a digestibilidade do EE (Tabela 8).

A análise do segundo contraste (controle vs suplementados) mostrou diferença $(\mathrm{P}<0,10)$ no consumo de todos os nutrientes com o consumo de suplemento (Tabela 8). Efeito quadrático $(\mathrm{P}<0,10)$ foi observado para o consumo de NDT, NDT \% e para o GMD, com valores máximos de 5,15 kg, 64,67\% e 0,91 kg/dia para consumos de suplemento de 2,88; 2,62 e 2,69 kg, respectivamente. Esse comportamento reflete o efeito quadrático também observado para a digestibilidade de todos os nutrientes analisados (Tabela 8). Os coeficientes de digestibilidade da MS, MO, PB, EE, FDN e CNF tiveram valores máximos de 64,06; 64,22; 72,44; 69,36; 60,45; e 87,13\% para consumos de 2,26; 2,56; 2,69; 2,35; 1,46; e 2,70 kg de suplemento.

O platô do GMD foi atingido quando a digestão da FDN foi máxima, ou seja, quando o consumo de suplemento foi de $1,46 \mathrm{~kg} /$ dia, ou seja, aproximadamente $400 \mathrm{~g}$ de PB (Figura 2).

Tabela 7 - Composição química e bromatológica do pasto no experimento 2

\begin{tabular}{lc}
\hline Item & Brachiaria decumbens (pastejo simulado) \\
\hline Matéria seca & 29,14 \\
Matéria orgânica (\% MS) & 92,09 \\
Proteína bruta (\% MS) & 8,66 \\
Nitrogênio insolúvel em detergente neutro (\%N-total) & 26,51 \\
Nitrogênio insolúvel em detergente ácido (\%N-total) & 21,30 \\
Extrato etéreo (\% MS) & 2,31 \\
Fibra em detergente neutro (\% MS) & 73,60 \\
Carboidratos não-fibrosos (\% MS) & 7,52 \\
Fibra em detergente ácido (\% MS) & 36,14 \\
Lignina (\% MS) & 5,88 \\
Fibra em detergente neutro indigestível (\% MS) & 14,58 \\
Fibra em detergente ácido indigestível (\% MS) & 8,42 \\
\hline
\end{tabular}


Tabela 8 - Consumos (kg/dia), teor de nutrientes digestíveis totais (\%), ganho médio diário (kg/dia) e digestibilidade de nutrientes em bovinos recebendo diferentes quantidades de suplemento

\begin{tabular}{|c|c|c|c|c|c|c|c|}
\hline \multirow[t]{2}{*}{ Item } & \multicolumn{4}{|c|}{ Tratamentos } & \multirow[t]{2}{*}{ EP } & \multicolumn{2}{|c|}{ Efeito } \\
\hline & 0 & 0,33 & 0,66 & 1,00 & & Linear & Quadrático \\
\hline \multicolumn{8}{|c|}{ Total } \\
\hline Matéria orgânica ${ }^{2}$ & 56,73 & 61,68 & 62,54 & 64,11 & 0,93 & 0,03 & ns \\
\hline Proteína bruta ${ }^{3}$ & 42,76 & 58,46 & 66,74 & 76,14 & 1,37 & 0,01 & ns \\
\hline Extrato etéreo ${ }^{4}$ & 65,78 & 67,46 & 73,96 & 74,56 & 0,80 & 0,01 & ns \\
\hline \multicolumn{8}{|c|}{ Ruminal } \\
\hline Matéria $\operatorname{seca}^{7}$ & 50,45 & 55,98 & 63,12 & 64,93 & 1,22 & 0,01 & ns \\
\hline Matéria organica ${ }^{8}$ & 56,92 & 61,25 & 63,00 & 64,98 & 1,36 & 0,07 & ns \\
\hline Proteína bruta99,15 & $-24,34$ & 13,21 & 22,38 & 31,19 & 2,55 & 0,01 & ns \\
\hline Extrato etéreo ${ }^{10,15}$ & $-11,62$ & $-8,51$ & $-2,21$ & 0,94 & 1,30 & 0,01 & ns \\
\hline Fibra em detergente neutro & 93,95 & 90,26 & 91,88 & 89,64 & 1,42 & ns & ns \\
\hline Proteína bruta ${ }^{13,15}$ & 53,39 & 53,10 & 57,10 & 65,19 & 1,38 & 0,02 & ns \\
\hline Extrato etéreo ${ }^{14,15}$ & 69,44 & 69,86 & 74,31 & 74,27 & 0,88 & 0,05 & ns \\
\hline Fibra em detergente neutro & 6,55 & 9,74 & 8,12 & 10,35 & 1,12 & ns & ns \\
\hline
\end{tabular}

Significativo $\mathrm{P}<0,10 .{ }^{1} \hat{Y}=7,3427+0,2358 X\left(R^{2}=0,6708\right) .{ }^{2} \hat{Y}=6,7422+0,2434 X\left(R^{2}=0,7471\right) .{ }^{3} \hat{Y}=0,6343+0,2175 X\left(R^{2}=0,9964\right)$.

${ }^{4} \mathrm{Y}=0,1688+0,0123 X\left(\mathrm{R}^{2}=0,9285\right) \cdot{ }^{5} \hat{Y}=5,3997-0,2915\left(\mathrm{R}^{2}=0,8557\right) \cdot{ }^{6} \hat{Y}=0,5397+0,3717 X\left(\mathrm{R}^{2}=0,9996\right) .{ }^{7} \hat{Y}=3,7185+0,9917 \mathrm{X}-0,1719 \mathrm{X}^{2}\left(\mathrm{R}^{2}=0,9596\right)$.

${ }^{8} \hat{Y}=51,0884+10,3804 X-1,9826 X^{2}\left(R^{2}=0,9999\right) .{ }^{9} \hat{Y}=0,3975+0,3833 X-0,0711 X^{2}\left(R^{2}=0,9773\right) \cdot{ }^{10} \hat{Y}=2,1072+0,0717 X\left(R^{2}=0,6271\right)$.

$11 \hat{Y}=52,6423+10,0986 X-2,2311 X^{2}\left(R^{2}=0,9991\right) .12 \hat{Y}=54,1397+7,8773 X-1,5388 X^{2}\left(R^{2}=0,9591\right) .13 \hat{Y}=47,9106+18,2653 X-3,3999 X^{2}\left(R^{2}=0,9925\right)$.

$14 \hat{Y}=53,9208+13,1366 X-2,7943 X^{2}\left(R^{2}=0,9844\right) .{ }^{15} \hat{Y}=55,4877+6,7813 X-2,3164 X^{2}\left(R^{2}=0,9935\right) .16 \hat{Y}=45,2919+30,9685 X-5,7299 X^{2}\left(R^{2}=0,9866\right)$.

$\mathrm{C}=$ tratamento controle (sal mineral); $\mathrm{M}=$ mantença; $\mathrm{S}=$ suplementados.

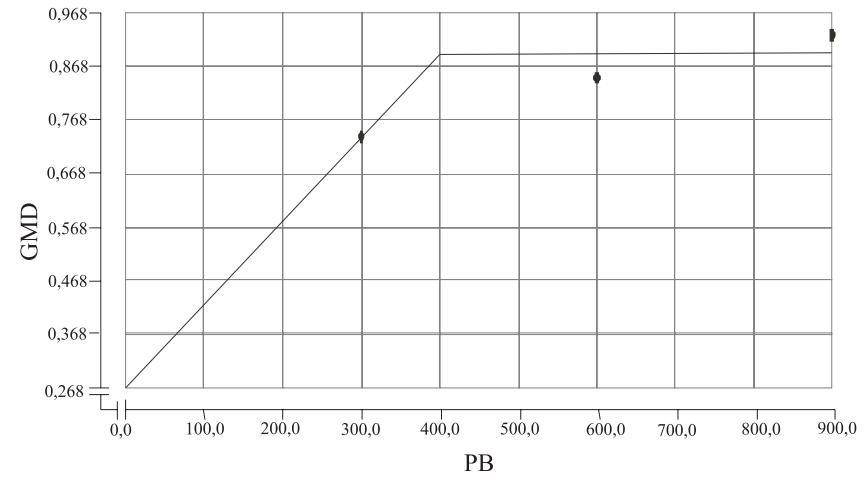

Figura 2 - Comportamento descritivo para a relação entre a quantidade de proteína bruta (PB) da dieta (g) e o ganho médio diário (kg).

Assim, pode-se inferir que bovinos terminados na transição águas-secas devem apresentar respostas ótimas com a suplementação de $400 \mathrm{~g}$ de PB.

Nas condições deste estudo, o consumo de MS de pasto estimado usando a regressão: $\mathrm{CMS}=7,3427+0,2358$ * suplemento seria de 6,40 kg, quando o CMS de suplemento resultou no ganho ótimo de peso, o consumo total de PB na transição seria de 6,36 * 86,60 + 400 g = 954,77 g de PB. Essa poderia ser considerada a exigência de $\mathrm{PB}$ para bovinos no período de transição águas-seca. Esse valor é próximo ao citado pelo BR - Corte (Valadares Filho et al., 2006b) para machos zebuínos inteiros de 350 kg com ganho diário de 900 g/dia que seriam de aproximadamente $967 \mathrm{~g}$ PB/dia.

Quando foi avaliado o contraste 1, observou-se diferença $(\mathrm{P}<0,10)$ somente para a excreção de alantoína entre os animais da mantença e da dieta-controle (Tabela 9). Embora os animais da dieta-controle tenham ingerido maiores teores de NDT e de PB (Tabela 8), a PBmic não apresentou diferença entre os dois tratamentos embora numericamente o valor obtido para a dieta-controle tenha sido superior (Tabela 9).

Para o contraste 2 , verificou-se aumento $(\mathrm{P}<0,10)$ para alantoína, purinas totais e PBmic com a suplementação. Quando analisados os níveis de suplemento, notou-se comportamento quadrático $(\mathrm{P}<0,10)$ para alantoína, purinas totais e PBmic com valores máximos de 184,47 mmol/dia; 202,70 mmmol/dia e 696,83 g/dia para consumo de 2,35; 2,31 e 2,31 kg de suplemento.

A eficiência microbiana não foi influenciada $(\mathrm{P}>0,10)$ pelos níveis de suplemento para nenhum dos contrastes analisados (Tabela 9), apresentando valor médio de 13,4 g PBmic/100 g NDT, valor próximo ao proposto pelo NRC (2001) de $13 \mathrm{~g}$ PBmic/100 g NDT.

Moraes et al. (2009), em pesquisa com bovinos a pasto, encontraram valor de eficiência de 11,8 g PB/100 g NDT, inferior ao detectado para este trabalho. Também Valadares Filho et al. (2006a) calcularam valor médio de 12 g PB/100 g NDT, considerado referência para condições tropicais. 
Tabela 9 - Derivados urinários de purinas, eficiência microbiana e proteína bruta microbiana em bovinos recebendo diferentes quantidades de suplemento

\begin{tabular}{|c|c|c|c|c|c|c|c|c|c|c|}
\hline \multirow[t]{2}{*}{ Item } & \multicolumn{5}{|c|}{ Tratamentos } & \multirow[t]{2}{*}{ EP } & \multicolumn{4}{|c|}{ Contrastes } \\
\hline & C & $\mathrm{M}$ & 1 & 2 & 3 & & $\mathrm{MxC}$ & $\mathrm{CxS}$ & $\mathrm{L}$ & Q \\
\hline Alantoína (mmol/dia $)^{1}$ & 130,3 & 104,6 & 164,5 & 184,9 & 179,7 & 3,93 & 0,08 & 0,01 & 0,01 & 0,05 \\
\hline Purinas totais $(\mathrm{mmol} / \mathrm{dia})^{2}$ & 145,8 & 121,8 & 181,3 & 204,5 & 196,9 & 4,19 & ns & 0,01 & 0,01 & 0,04 \\
\hline Eficiência microbiana (gNmic/100gNDT) & 12,5 & 14,2 & 12,9 & 14,4 & 12,9 & 0,35 & ns & ns & ns & ns \\
\hline Proteína bruta microbiana $(\mathrm{g} / \mathrm{dia})^{3}$ & 445,9 & 370,3 & 606,5 & 703,8 & 670,8 & 17,38 & ns & 0,01 & 0,01 & 0,04 \\
\hline
\end{tabular}

${ }^{1} \hat{Y}=129,5844+46,6209 X-9,9003 X^{2}\left(R^{2}=0,9953\right) ;{ }^{2} \hat{Y}=144,3964+50,3532 X-10,8715 X^{2}\left(R^{2}=0,9902\right) ;{ }^{3} \hat{Y}=450,8415+213,2832 X-46,2305 X^{2}\left(R^{2}=0,9903\right)$.

Zervoudakis (2003), Vilela (2004) e Moraes et al. (2009), em condições semelhantes às deste estudo, também não encontraram diferenças na eficiência microbiana entre os tratamentos e relataram valores médios de 11,74; 11,70 e 11,90 g de PBmic/100 g de NDT, respectivamente.

\section{Conclusões}

A digestão total da fibra em detergente neutro no período de transição águas-seca é máxima quando o consumo de suplemento encontra-se em torno de $1,5 \mathrm{~kg} / \mathrm{dia}$, o que resulta em resposta ótima para o ganho médio diário com a suplementação de $400 \mathrm{~g}$ de proteína bruta. No período de transição águas-seca, a suplementação de até $3 \mathrm{~kg} /$ dia não altera a digestão ruminal da fibra em detergente neutro. A suplementação em torno de $1,0 \%$ do peso corporal proporciona maior aporte de proteína microbiana para o animal.

\section{Referências}

BODINE, T.N.; PURVIS II, H.T.; LALMAN, D.L. Efects of supplement type on animal performance, forage intake, digestion, and ruminalmeasurementsof growing beef cattle. Journal of Animal Science, v.79, n.4, p.1041-1051, 2001. CARVALHO, A.U.; VALADARES FILHO, S.C.; COELHO DA SILVA, J.F. et al. Níveis de concentrado em dietas de zebuínos. 1. Consumo e digestibilidade aparente. Revista Brasileira de Zootecnia, v.26, n.5, p.986-995, 1997.

CECAVA, M.J.; MERCHEN, N.R.; GAY, L.C. et al. Composition of ruminal bacteria harvest from steers as influenced by dietary energy level, feeding frequency, and isolation techniques. Journal of Dairy Science, v.73, n.9, p.2480-2488, 1990.

CHEN, X.B.; GOMES, M.J. Estimation of microbial protein supply to sheep and cattle based on urinary excretion of purine derivatives - an overview of technical details. Bucksburnd, Aberdeen: Rowett Research Institute; International Feed Resources Unit. 1992. 21p. (Occasional publication).

CHIZZOTI, M.L.; VALADARES FILHO, S.C.; LEÃO, M.I. et al. Casca de algodão em substituição parcial à silagem de capimelefante para novilhos. 2. Parâmetros ruminais e séricos, produção microbiana e excreção urinária de compostos nitrogenados. Revista Brasileira de Zootecnia, v.34, n.6, p.2103-2111, 2005.

DETMANN, E.; PAULINO, M.F.; VALADARES FILHO, S.C. et al. Níveis de proteína em suplementos para terminação de bovinos em pastejo durante o período de transição seca/águas: digestibilidade aparente e parâmetros do metabolismo ruminal e dos compostos nitrogenados. Revista Brasileira de Zootecnia, v.34, n.4, p.1380-1391, 2005.

DIAS, H.L.C.; VALADARES FILHO, S.C.; COELHO DA SILVA, J.F. et al. Eficiência de síntese microbiana, $\mathrm{pH}$ e concentrações ruminais de amônia em novilhos $\mathrm{F} 1$ Limousin $\mathrm{x}$ Nelore alimentados com dietas contendo cinco níveis de concentrado. Revista Brasileira de Zootecnia, v.29, n.4, p.555-563, 2000.

FUJIHARA, T.; ØRSKOV, E.R.; REEDS, P.J. et al. The effect of protein infusion on urinary excretion of purine derivatives in ruminants nourished by intragastric nutrition. Journal of Agricultural Science, v.109, n.2, p.7-12, 1987.

HALL, M.B. Calculation of non-structural carbohydrate content of feeds that contain no-protein nitrogen. Gainesville: University of Florida, 2000. P.A-25 (Bulletin 339, April-2000).

KIMURA, F.T.; MILLER, V.L. Improved determination of chromic oxide in cow feed and feces. Journal of Agriculture and Food Chemistry, v.5, n.3, p.216-227, 1967.

LADEIRA, M.M.; VALADARES FILHO, S.C.; LEÃO, M.I. et al Eficiência microbiana, Concentração de amônia e pH ruminal e perdas nitrogenadas endógenas, em novilhos nelore. Revista Brasileira de Zootecnia, v.28, n.2, p.404-411, 1999.

LICITRA, G.; HERNANDEZ, T.M.; VAN SOEST, P.J. Standardization of procedures for nitrogen fractionation of ruminant feeds. Animal Feed Science and Technology, v.57, n.4, p.347-358, 1996.

MAYER, D.G.; STUART, M.A.; SWAIN, A.J. Regression of realworld data on model output: an appropriate overall test of validity. Agricultural System, v.45, n.2, p.93-104, 1994.

MARTÍN-ORÚE, S.S.; BALCELLS, J.; GUADA, J.A. et al. Microbial mitrogen production in growing heifers: direct measurement of duodenal flow of purine bases versus urinary excretion of purine derivatives as estimation procedures. Animal Feed Science and Technology, v.88, n.2, p.171-188, 2000.

MERTENS, D.R. Gravimetric determination of amylase treated neutral detergent fiber in feeds with refluxing in beakers or crucibles: collaborative study. Journal of AOAC International, v.85, n.6, p.1212-1240, 2002.

MIERES, J.M. Tipo de suplemento y su efecto sobre el forraje. In: MARTINS, D.N. (Ed.) Suplementacion estratégica para el engorde de ganado. Montevideo: INIA, 1997. p.11-15. (Serie Técnica, 83).

MORAES, E.H.B.K.; PAULINO, M.F.; MORAES, K.A.K. et al. Uréia em suplementos protéicos-energéticos para bovinos de corte durante o período da seca: características nutricionais e ruminais. Revista Brasileira de Zootecnia, v.38, n.4, p.770777, 2009.

NATIONAL RESEARCH COUNCIL - NRC. Nutrient requirements of beef cattle. 7.ed. Washington, D.C.: National Academy Press, 1996. 242p.

NATIONAL RESEARCH COUNCIL - NRC. Nutrient requirements of dairy cattle. 7.ed. Washington, D.C.: National Academy Press, 2001. 381p. 
PAULINO, M.F.; FIGUEIREDO, D.M.; MORAES, E.H.B.K. et al. Suplementação de bovinos em pastagens: uma visão sistêmica. In: SIMPÓSIO DE PRODUÇÃO DE GADO DE CORTE, 4., 2004, Viçosa, MG. Anais... Viçosa, MG: SIMCORTE, 2004. p.93-144.

PAULINO, M.F.; DETMANN, E.; VALADARES FILHO, S.C. Bovinocultura funcional nos trópicos. In: SIMPÓSIO DE PRODUÇÃO DE GADO DE CORTE, 6., 2008, Viçosa, MG. Anais... Viçosa, MG: SIMCORTE, 2008. p.275-306.

PEREZ, J.F.; BALCELLS, J.; GUADA, J.A. et al. Determination of rumen microbial-nitrogen production in sheep: a comparison of urinary purine excretion with methods using ${ }^{15} \mathrm{~N}$ and purine bases as markers of microbial-nitrogen entering the duodenum. British Journal of Nutrition, v.75, n.3, p.699-709, 1996.

PUCHALA, R.; KULASEK, G.W. Estimation of microbial protein flow from the rúmen of sheep using microbial nucleic acid and excretion of purine derivatives. Canadian Journal of Animal Science, v.72, n.4, p.821-830, 1992.

RENNÓ, L.N.; VALADARES, R.F.D.; LEÃO, M.I. et al. Estimativa da produção de proteína microbiana pelos derivados de purinas na urina em novilhos. Revista Brasileira de Zootecnia, v.29, n.6, p.1223-1234, 2000.

SAMPAIO, C.B. Consumo, digestibilidade e dinâmica ruminal em bovinos alimentados com forragem tropical de baixa qualidade suplementados com compostos nitrogenados. 2007. 53f. Dissertação (Mestrado em Zootecnia) - Universidade Federal de Viçosa, Viçosa, MG.

STATISTICAL ANALYSIS SYSTEM - SAS. Institute SAS/STAT software: changes and enhancements through release 6.12. Cary: Statistical Analysis System Institute, 1997. 1167p.

SILVA, D.J.; QUEIROZ, A.C. Análise de alimentos: métodos químicos e biológicos. 3.ed. Viçosa, MG: UFV, Imprensa Universitária, 2002. 165p.
USHIDA, K.; LASSALAS, B.; JOUANY, J.P. Determination of assay parameters for RNA analysis in bacterial and duodenal samples by spectrophotometry. Influence of sample treatment and preservation. Reproduction Nutrition Development, v.25, n.6, p.1037-1046, 1985

VALADARES FILHO, S.C.; MAGALHÃES, K.A.; ROCHA JUNIOR, V.R. et al. Tabelas brasileiras de composição de alimentos para bovinos. CQBAL 2.0. 2.ed. Viçosa, MG: Universidade Federal de Viçosa; Suprema Gráfica Ltda. 2006. 329p.

VALADARES FILHO, S.C.; PINA, D.S.; CHIZZOTTI, M.L. et al. Degradação ruminal da proteína dos alimentos e síntese de proteína microbiana. In: VALADARES FILHO, S.C.; PAULINO, P.V.R.; MAGALHÃES, K.A. (Eds.) Exigências nutricionais de zebuínos e tabelas de composição de alimentos BRCorte. 1.ed. Viçosa, MG: UFV, DZO, 2006a. 142p.

VALADARES FILHO, S.C.; PAULINO, P.V.R.; VALADARES, R.F.D. et al. Exigências nutricionais de zebuínos no Brasil. II. Proteína. In: VALADARES FILHO, S.C.; PAULINO, P.V.R.; MAGALHÃES, K.A. (Eds.) Exigências nutricionais de zebuínos e tabelas de composição de alimentos BR-Corte. 1.ed. Viçosa, MG: UFV, DZO, 2006b. 142p.

VAN SOEST, P.J.; ROBERTSON, J.B.; LEWIS, B.A. Methods for dietary fiber, neutral detergent fiber, and nonstarch polyssacarides in relation to animal nutrition. Journal of Animal Science, v.74, n.10, p.3583-3597, 1991.

VILLELA, S.D.J. Fontes de proteína em suplementos múltiplos para bovinos em pastejo. 2004. 116f. Tese (Doutorado em Zootecnia) - Universidade Federal de Viçosa, Viçosa, MG.

ZERVOUDAKIS, J.T. Suplementos múltiplos de autocontrole de consumo e freqüência de suplementação na recria de novilhos durante os períodos das águas e transição águasseca. 2003. 78f. Tese (Doutorado em Zootecnia) - Universidade Federal de Viçosa, Viçosa, MG. 